\title{
Study on Flight Performance of Propeller-Driven UAV
}

\author{
Rui-lin Liu, ${ }^{1}$ Zhong-jie Zhang $\mathbb{D}^{1}{ }^{1}$ Yu-fei Jiao, ${ }^{1}$ Chun-hao Yang, ${ }^{2}$ and Wen-jian Zhang ${ }^{1}$ \\ ${ }^{1}$ Army Military Transportation University, Tianjin 300161, China \\ ${ }^{2}$ Naval University of Engineering, Wuhan 430033, China
}

Correspondence should be addressed to Zhong-jie Zhang; jjxyzzj@163.com

Received 8 November 2018; Revised 11 January 2019; Accepted 11 February 2019; Published 21 April 2019

Academic Editor: Timothy Lee

Copyright (c) 2019 Rui-lin Liu et al. This is an open access article distributed under the Creative Commons Attribution License, which permits unrestricted use, distribution, and reproduction in any medium, provided the original work is properly cited.

The engine performance test at altitudes of 0-7000 m was carried out on the high-performance test bench of the Unmanned Aerial Vehicle (UAV) piston engine. The flight performance of UAV was studied, including propeller thrust characteristics, maneuverability, flight envelope, and cruise performance. The results showed that with the increase in altitudes, the UAV climb rate gradually decreased; the maximum climb rate decreased from $2.5 \mathrm{~m} / \mathrm{s}$ at $2000 \mathrm{~m}$ to $0.5 \mathrm{~m} / \mathrm{s}$ at $7000 \mathrm{~m}$. The maximum flight altitude is $7000 \mathrm{~m}$, and the flight speed range is about $47 \mathrm{~m} / \mathrm{s}-52 \mathrm{~m} / \mathrm{s}$ at the altitude of $7000 \mathrm{~m}$. Maximum navigation range and endurance of UAV decrease by $5.8 \%$ and $8 \%$, respectively, with each increment of $1000 \mathrm{~m}$ in altitudes.

\section{Introduction}

UAV are popular among various militaries due to their fast discovery, tracking, hit static/dynamic targets, low cost, and high security [1-3]. The piston engine is regarded as the "heart" of UAV, and UAV matched with the engine can achieve the task of reconnaissance/strike $[4,5]$. When the piston engine of UAV operates at high altitudes, the power and torque decrease due to the decrease in intake air affected by a decrease in air density and air Reynolds number, which directly affects flight performance parameters of the UAV including propeller efficiency, speed, climbing rate, maximum range, and flight time of the UAV [6-8].

At present, the main research institutions here and abroad focused on the design of the propeller blade profile, the high-altitude thrust characteristic of the propeller, the relationship between the efficiency of the propeller and the flight height, and the matching of the propeller with the engine at high altitudes. Wang [9] optimized the key geometric parameters of the UAV propeller to achieve a maximum lift and drag ratio by using the particle swarm optimization algorithm. Shan et al. [10] matched the two-stage turbocharged system with a piston engine in a simulation method and studied the high-altitude flight characteristics of the engine propeller propulsion system. Two regulation laws of the engine full power and the power decline were analyzed.
Zijie et al. [11] studied the power output characteristics of a two-stroke engine and the power absorption characteristics of the fixed pitch propeller and obtained a method for matching the fixed pitch propeller with the engine at low altitudes. Manqun et al. [12] studied the variation of propeller thrust, driving power, and propeller performance curve under different simulated wind speeds by using a highaltitude simulated test bench. They coupled the external characteristic curve of the engine with the performance curve of the propeller and evaluated the thrust limit of the system and the comprehensive performance of the driving force-wind speed-fuel consumption.

Zhang [13] found that the effective power of the propeller piston engine decreases with the increase in height. Efficiency of the propeller and available power of the UAV were proportional to the cruising speed when the flight altitude is constant, and the efficiency and the available power are inversely proportional to flight altitudes when the cruising speed was certain. Ma and Song [14] and Wang et al. [15] summarized the method of improving the propeller efficiency in the entire flight envelope range, including the selection of the basic blade profile of the propeller which combined low Reynolds number with a high lift-drag ratio, relaxing the upper limit of the Mach number of the propeller tip, and reasonable matching of the propeller absorption power with the output power of the engine. 


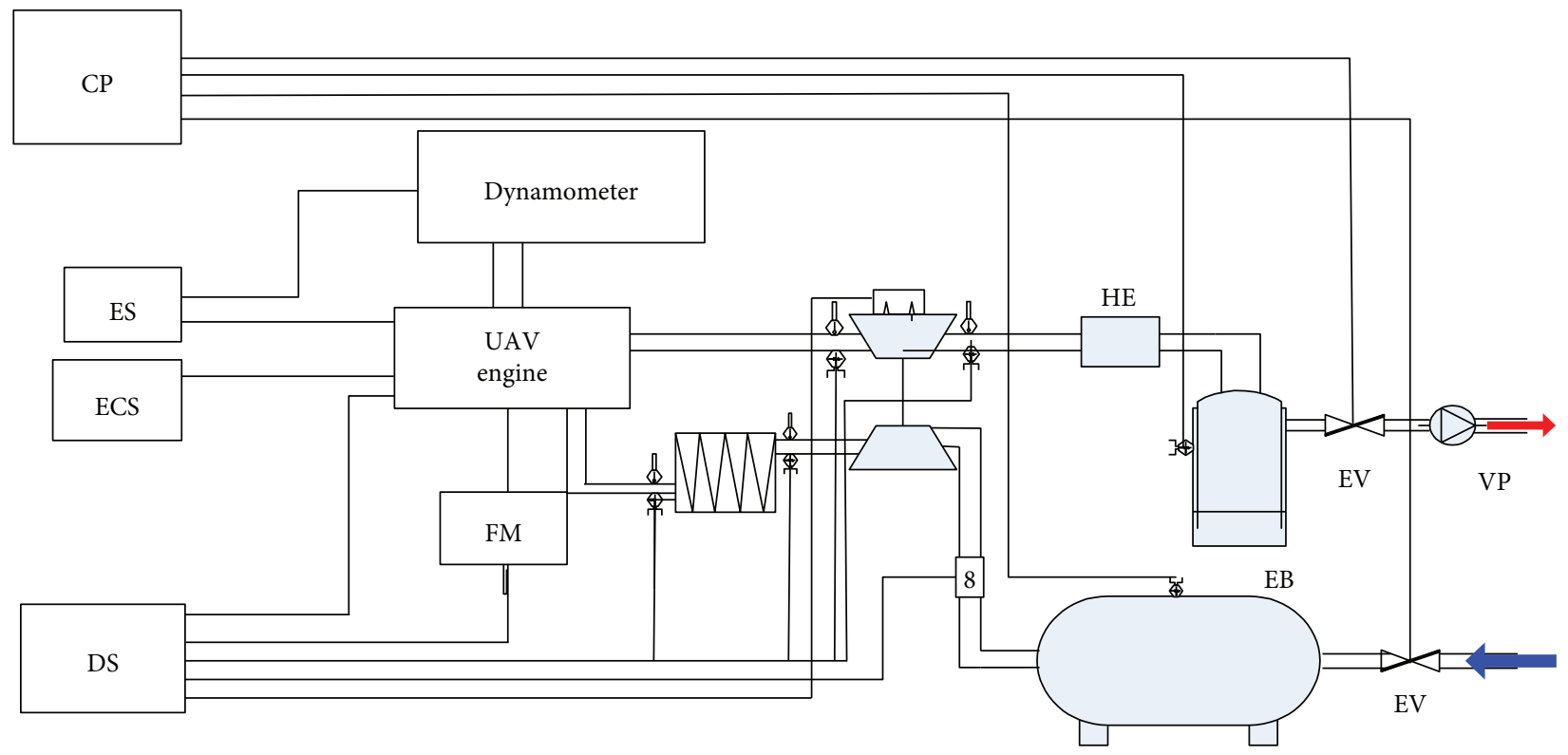

IB

Figure 1: Performance simulation test system for the UAV engine at high altitudes.

He et al. [16] established the relationship of thrust, engine speed, flying height, and flight speed from a six-degree-offreedom motion equation of UAV (flight time, yaw angle, pitch angle, roll angle, flight height, airspeed, elevator deflection angle, and aileron angle). Hallissy and Chattot [17] and Smedresman et al. [18] proposed the propeller vortex theory (strip theory) to evaluate aerodynamic characteristics of propellers. Zhang [19] used empirical formulas and curve to estimate the available power of the propeller engine and selected suitable propeller.

At present, major researches on high-altitude performance of UAV are performed below the altitude of $3000 \mathrm{~m}$. With the equipment of UAV, flying altitudes are generally above $7000 \mathrm{~m}$. It is significant to study technological enhancement of high-altitude performance of UAV at the altitude from $0 \mathrm{~m}$ to $7000 \mathrm{~m}$. The most important limiting factor of the flight performance parameters of UAV is the engine's high-altitude performance. The paper adopted empirical formulas and theoretical derivation to get the flight performance change law of the propeller thrust characteristic, maneuver performance (climbing rate, minimum turning radius), and flight range and navigation time based on previous bench test results of the UAV piston engine.

\section{High-Altitude Simulation Test of an Opposed-Piston Gasoline Engine and Its Matching with UAV}

The paper studies the power, economy, and thermal balance performance of the opposed-piston engine that relied on the Key Laboratory of Power Machinery for Plateau Adaptation. The simulation test system (as shown in Figure 1) for the high-altitude performance of the engine is composed of low-pressure simulation system, high-altitude

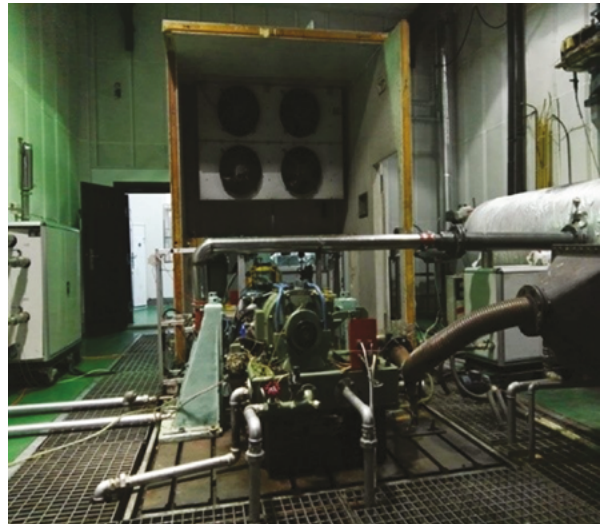

FIgURE 2: Simulation test bench of the gasoline engine for simulating high altitudes.

cooling simulation system, engine state monitoring system, and engine control system [20], which can simulate the air pressure and cooling environment at altitudes of 0-7000 m.

2.1. Opposed-Piston Gasoline Engine for Test Research. Figure 2 shows the test bench of the gasoline engine for simulating high altitudes. The UAV engine is an opposed-piston gasoline engine (as shown in Figure 3), and the main technical parameters were shown in Table 1 . The fuel supply system of the engine has a dual carburetor structure to achieve the purpose of uniform oil supply (as shown in Figure 3) [21]. The high-altitude performance test of the engine was carried out with reference to the performance test method of the automotive engine (GB-T18927-2001) and the general technical requirements for the adaptability of logistics equipment at a plateau environment (GJB-7251-2011). The changes in power, torque, fuel consumption rate, heat load, and heat flow distribution were studied under external characteristics 


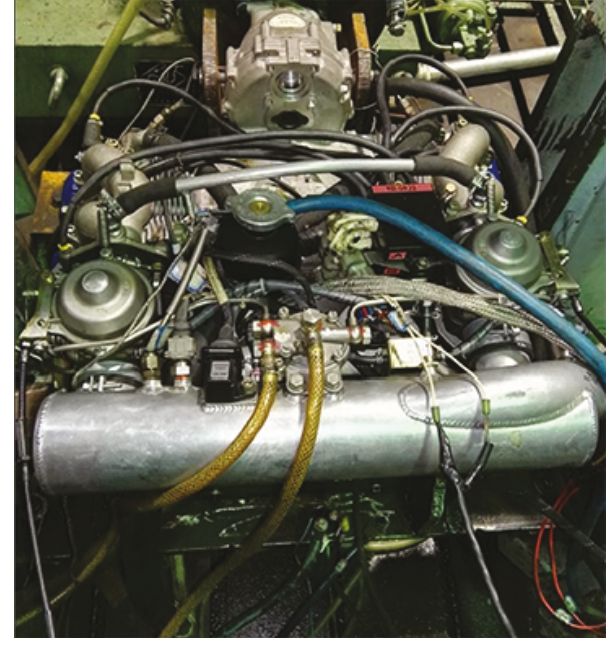

FIgURE 3: The gasoline engine of UAV with double carburetors.

TABLe 1: Technical parameters of the Rotax gasoline engine.

\begin{tabular}{lc}
\hline Name & UL/F aeroengine \\
\hline Type & $\begin{array}{c}\text { Four-cylinder, four-stroke, and } \\
\text { horizontally opposed engine }\end{array}$ \\
Displacement & $12 \mathrm{~L}$ \\
Bore $\times$ stroke & $79.5 \mathrm{~mm}^{*} 61.0 \mathrm{~mm}$ \\
Compression ratio & $9: 1$ \\
Rated power & $73.5 \mathrm{~kW} / 5500 \mathrm{rpm}$ \\
Maximum torque & $144 \mathrm{~N} \cdot \mathrm{m} / 4900 \mathrm{rpm}$ \\
Cooling mode & Mixed cooling \\
\hline
\end{tabular}

at $0-7000 \mathrm{~m}$ altitudes to evaluate power, economy, and heat balance performance.

2.2. Simulation of the Cooling Air Environment. Forced convection of cooling air was strengthened by fairing to cool the cylinder block. Figure 4 introduces the working principle of the fairing.

At experimental conditions, we simulate high-altitude wind using two fans, because cooling the heat of the fan to the cylinder block radiator is equal to theoretical heat dissipation of the cylinder block radiator when UAV is flying at high altitudes (see the equation below).

$$
Q_{s}=Q_{m},
$$

where $Q_{s}$ represents the theoretical heat dissipation of the cylinder block radiator when UAV is flying at high altitude $(\mathrm{kW})$ and $Q_{m}$ represents the simulated heat dissipation under the testbed $(\mathrm{kW})$.

Theoretical heat dissipation of the cylinder block radiator under different air convection velocities and different altitudes was calculated as follows:

$$
Q_{s}=A \cdot \alpha \cdot\left(t_{w}-t_{f}\right),
$$

where $A$ represents the total area of the cylinder block radiator $\left(\mathrm{m}^{2}\right), \alpha$ represents the heat transfer coefficient $\left(\mathrm{W} / \mathrm{m}^{2} \cdot \mathrm{K}\right)$,

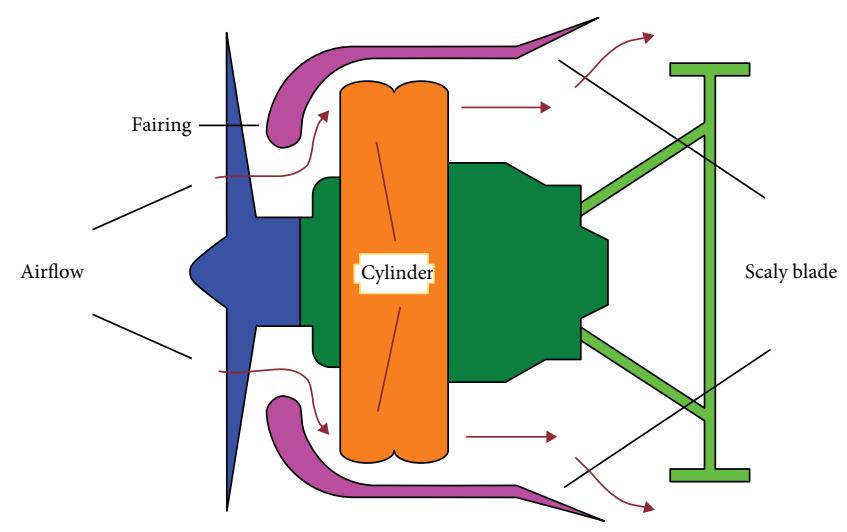

FIGURE 4: Working principle diagram of UAV rectifier fairing.

$t_{w}$ represents the surface temperature of the cylinder block $\left({ }^{\circ} \mathrm{C}\right)$, and $t_{f}$ represents the environmental temperature $\left({ }^{\circ} \mathrm{C}\right)$.

The air convection heat transfer coefficient $\alpha$ at the altitude of $0 \mathrm{~m}$ was calculated as follows:

$$
\alpha=207 \times\left[0.0247-0.00372 \times\left(\frac{h^{0.8}}{t^{0.4}}\right)\right] \cdot V^{0.73},
$$

where $h$ represents the height of the radiator $(\mathrm{cm}), t$ represents the distances between the fins $(\mathrm{cm})$, and $V$ represents the air velocity $(\mathrm{km} / \mathrm{h})$.

Among them, $h=2.0 \mathrm{~cm}, t=0.6 \mathrm{~cm}$, and $V=100 \mathrm{~km} / \mathrm{h}$ $200 \mathrm{~km} / \mathrm{h}$. The air convection heat transfer coefficient $\alpha$ at $0 \mathrm{~m}$ is equal to $3.084 \cdot V^{0.73}$. The air convection heat transfer coefficient of the radiator is proportional to the atmospheric density to the power of 0.7 . The air convection heat transfer coefficient at different altitudes is relative to the coefficient at $0 \mathrm{~m}$ :

$$
\alpha_{H}=\alpha_{0}\left(\frac{\rho_{H}}{\rho_{0}}\right)^{0.7}
$$

The total area of the cylinder block radiator $A$ is equal to $2.49 \mathrm{~m}^{2}$. The surface temperature range of the cylinder block was between $100^{\circ} \mathrm{C}$ and $150^{\circ} \mathrm{C}$. We selected the maximum temperature as $150^{\circ} \mathrm{C}$. Heat dissipating capacity of the opposed-piston engine block was calculated by formulas (2), (3), and (4).

From Figure 5, theoretical heat dissipating capacity of the block $Q_{s}$ was from $23 \mathrm{~kW}$ to $47 \mathrm{~kW}$. According to formula (1), wind velocity of the fans was calculated. High-altitude air convection was simulated using two fans, and air velocity across by the engine radiator was measured using a wind speed measuring instrument, which can reflect the real high-altitude cooling environment. Forced convective wind speed was above $10 \mathrm{~m} / \mathrm{s}$ from formula (2). We adjusted the air supply distances and angle of fans, and the measured maximum wind speed is $11.3 \mathrm{~m} / \mathrm{s}$ to meet the maximum heat dissipation requirement (as shown in Figure 6).

We investigated the results of engine performance at simulated high altitudes to evaluate UAV flying quality. Flight 


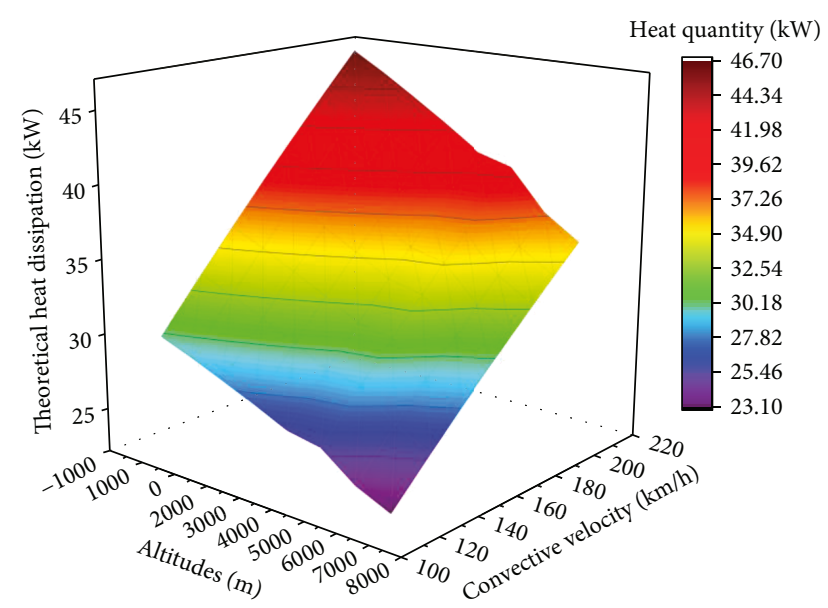

FIgURE 5: Theoretical heat dissipating capacity at high altitudes.

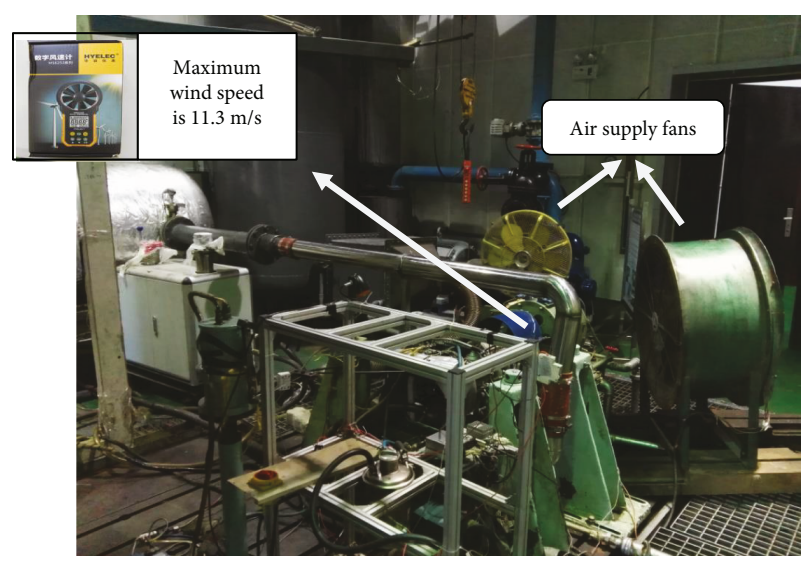

Figure 6: Cooling air condition simulation bench at high altitudes.

performance of UAV [22] contains propeller thrust characteristic, maneuverability, flight envelope, and cruise performance (see Table 2). Figures 7 and 8 are the variations of the output power and torque of the piston engine with altitudes. Experimental results showed that the torque and power decrease with increasing altitudes, and circumstances become worse with higher altitudes.

The main parameters of the surveillance and strike UAV are selected as shown in Table 3 [24].

There are two methods for calculating the flight performance of UAV: the pull method and the power method. The power method was suitable for the situation in which power varies with speed, flight speed, and altitudes. The basic motion equation of UAV with power as a parameter is as follows:

$$
\left\{\begin{array}{l}
m \frac{d v}{d t}=\frac{N_{k}}{v} \cos (\alpha+\varphi)-\frac{N_{s}}{v}-G \sin \theta \\
m v \frac{d \theta}{d t}=\left[\frac{N_{k}}{v} \sin (\alpha+\varphi)+Y\right] \cos \gamma-G \cos \theta \\
m v \cos \theta \frac{d \varphi}{d t}=\left[L \frac{N_{k}}{v} \sin (\alpha+\varphi)+Y\right] \sin \gamma
\end{array}\right.
$$

The basic motion equation (5) of the UAV was simplified to a constant horizontal motion equation [13], assuming that the angle $(\alpha+\varphi)$ between the axis of the engine pulling force and the direction of the flight speed is very small and the track angle is small $(\cos \theta \approx 1)$. The motion equation of $\mathrm{UAV}$ is as follows:

$$
\begin{aligned}
& \left\{\begin{array}{l}
m \frac{d v}{d t}=T-D-G \sin \theta, \\
m v \frac{d \theta}{d t}=L \cos \gamma-G \cos \theta, \\
m v \cos \theta \frac{d \varphi}{d t}=L \sin \gamma,
\end{array}\right. \\
& \left\{\begin{array}{l}
m \frac{d v}{d t}=T-D-G \sin \theta, \\
m v \frac{d \theta}{d t}=L \cos \gamma-G \cos \theta, \\
m v \cos \theta \frac{d \varphi}{d t}=L \sin \gamma,
\end{array}\right.
\end{aligned}
$$

where $m$ is the weight of $\operatorname{UAV}(\mathrm{kg}), T$ is the thrust of the engine $(\mathrm{N} \cdot \mathrm{m}), D$ is the drag of UAV, $G$ is the gravity of $\mathrm{UAV}, L$ is the lift of UAV, $\theta$ is the tilt angle of the flight track, $\varphi$ is the azimuth of the flight track, $\gamma$ is the angle of the flight track, and $v$ is the flight speed of UAV.

\section{High-Altitude Flight Performance of UAV}

We combined high-altitude test results of the opposed-piston gasoline engine and theoretical derivation to study propeller characteristics, maneuverability, flight envelope, and endurance of the UAV at high altitudes.

3.1. High-Altitude Propeller Thrust Characteristics of UAV. Propeller thrust characteristic [22] is mainly evaluated by propeller efficiency and available power. The propeller efficiency is determined by the propeller efficiency $C_{p}-J$ curve (as shown in Figure 9). Between them, $J$ (the ratio between propeller distance $H_{a}$ and propeller diameter $D$ ) is the relative distance of the propeller and $C_{p}$ is the propeller power factor.

$$
\begin{aligned}
J & =\frac{H_{a}}{D}=\frac{v}{n_{c} D}, \\
C_{p} & =\frac{P_{x}}{\rho n_{c}^{3} D^{5}},
\end{aligned}
$$

where $v$ is the UAV flight speed $(\mathrm{m} / \mathrm{s}), \rho$ is the air density $\left(\mathrm{kg} / \mathrm{m}^{3}\right), n_{c}$ is the propeller speed $(\mathrm{r} / \mathrm{min}), D$ is the propeller diameter $(\mathrm{m})$, and $P_{x}$ is the available power of UAV $(\mathrm{kW})$.

The available power of UAV is the ratio of gravity and the lift-to-drag ratio $\left(C_{L} / C_{D}\right)$ at different altitudes and flying speeds, and its calculation formula is as follows:

$$
P_{x}=T V=\frac{G}{K} V=\frac{m g}{C_{L} / C_{D}} V,
$$


TABLE 2: Flight performance parameters of UAV.

\begin{tabular}{|c|c|c|}
\hline Flight performance & Performance index & Index meaning \\
\hline \multirow{2}{*}{$\begin{array}{l}\text { Propeller thrust } \\
\text { characteristics }\end{array}$} & Propeller efficiency & $\begin{array}{c}\text { The ability of the propeller to transform the output power of the engine into available } \\
\text { power }\end{array}$ \\
\hline & $\begin{array}{l}\text { Available power of the } \\
\text { propeller }\end{array}$ & The final output power of a propeller under a given operating condition \\
\hline \multirow{2}{*}{ Maneuverability } & Maximum climb rate & Maximum vertical velocity of UAV under given operating conditions \\
\hline & Minimum turning radius & The minimum horizontal turning radius of a UAV under given operating conditions \\
\hline \multirow{3}{*}{ Flight envelope } & Minimum flight speed & Stall speed of UAV at the maximum lift coefficient \\
\hline & Maximum flight speed & The maximum speed of the UAV under the maximum output power \\
\hline & Service ceiling & $\begin{array}{c}\text { The maximum altitude of the UAV under the maximum output power with a } \\
\text { climbing rate of } 0.5 \mathrm{~m} / \mathrm{s}\end{array}$ \\
\hline \multirow{2}{*}{ Duration performance } & Maximum range & The most distant flight distance of UAV under a given fuel consumption rate \\
\hline & Maximum endurance & The longest flight duration of UAV under the maximum output power \\
\hline
\end{tabular}

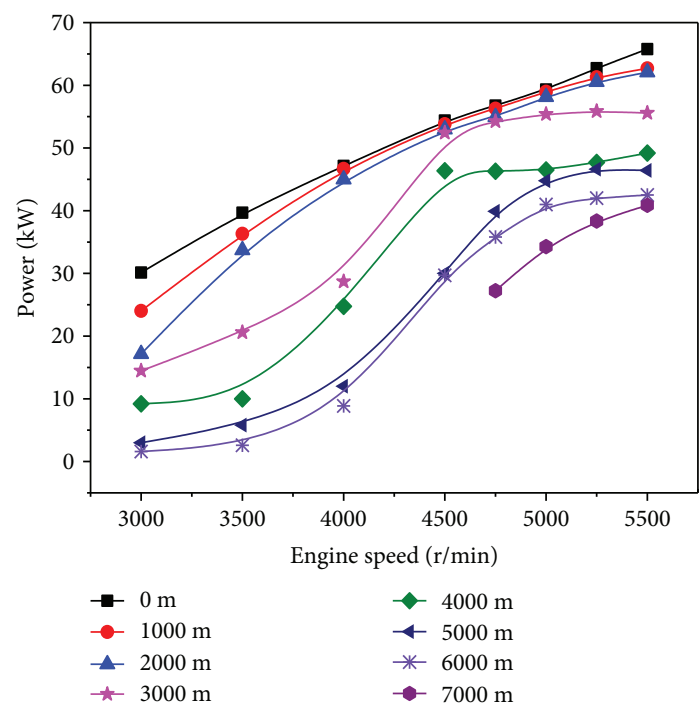

FIgURE 7: Output power curves at different altitudes.

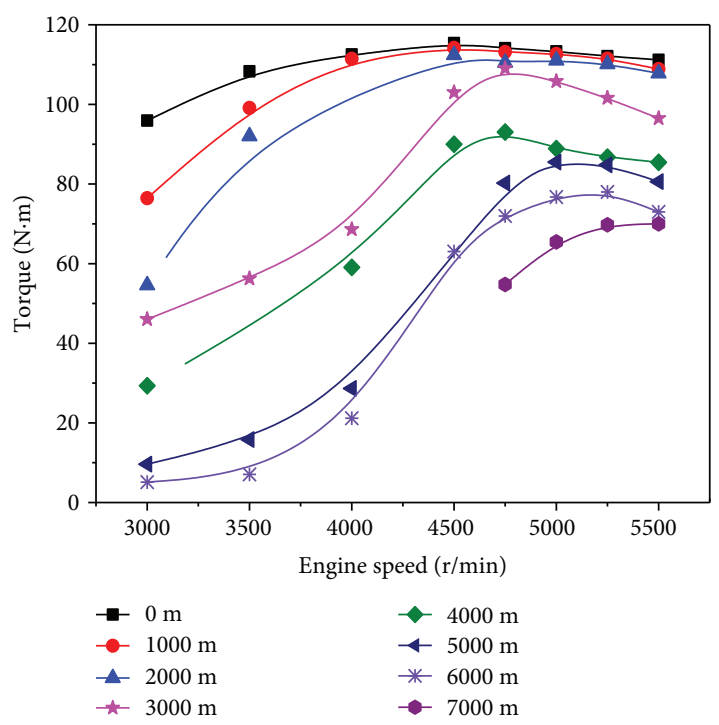

FIgURE 8: Output torque curves at different altitudes. where $m$ is the weight of the aircraft $(\mathrm{kg}), K$ is the lift-to-drag ratio of $\mathrm{UAV}, C_{L}$ is the lift coefficient, $C_{D}$ is the drag coefficient of UAV, and $V$ is the flight speed of UAV $(\mathrm{m} / \mathrm{s})$. The relative distance $J$ and the power coefficient $C_{p}$ were calculated by formulas (7) and (8), respectively. Flight altitude was above $2000 \mathrm{~m}$ when UAV is carrying out a mission. The power required for UAV under different flight speeds at a certain altitude was calculated through formula (9) (as shown in Figure 10).

The propeller efficiency was obtained from Figure 9. The available power of the propeller was calculated by formula (8). The efficiency and available power of the propeller at 2000 m-7000 m altitudes were shown in Figures 11 and 12.

The efficiency of the propeller increases with increasing altitudes, especially at high flight speeds (as shown in Figure 11), because the lift-drag ratio of UAV is limited by the shape of the wing when flying at high altitudes, and the ratio value increases slightly with the increase in the altitude.

The comparison of Figures 7 and 12 (the output power curve of a piston gasoline engine at different altitudes) showed that there is a difference between the power of the UAV and the output power of the engine at high flight speed. The output power of the engine increases with increasing flight speed, but the available power of the UAV exceeds the inflection point with increasing speed and the power remains basically unchanged when the speed exceeds the inflection point. It is mainly because the efficiency of the propeller decreases significantly at high flight speeds, and the efficiency of the engine output transforming into the available power is low.

3.2. High-Altitude Maneuverability. The maneuverability performance of UAV mainly includes climbing, horizontal hovering, and horizontal acceleration. The equation of motion of UAV in steady straight ascent is as follows:

$$
\left\{\begin{array}{l}
T \cos \left(\alpha+\varphi_{\mathrm{fd}}\right)=D+G \sin \theta, \\
L+T \sin \left(\alpha+\varphi_{\mathrm{fd}}\right)=G \cos \theta .
\end{array}\right.
$$


TABLE 3: The main parameters of UAV.

\begin{tabular}{llcc}
\hline Length & $8.13 \mathrm{~m}$ & Wing area & Height \\
Maximum width at the front of the fuselage & $1.12 \mathrm{~m}$ & Tail wing & $2.45 \mathrm{~m}^{2}$ \\
Maximum width behind the fuselage & $0.75 \mathrm{~m}$ & Aircraft upper body area & $4.38 \mathrm{~m}$ \\
Propeller diameter & $1.73 \mathrm{~m}$ & Weight of fuel & $19.17 \mathrm{~m}^{2}$ \\
Empty weight & $350 \mathrm{~kg}$ & Maximum takeoff weight & $295 \mathrm{~kg}$ \\
Maximum task load & $204 \mathrm{~kg}$ & $1020 \mathrm{~kg}$ \\
\hline
\end{tabular}

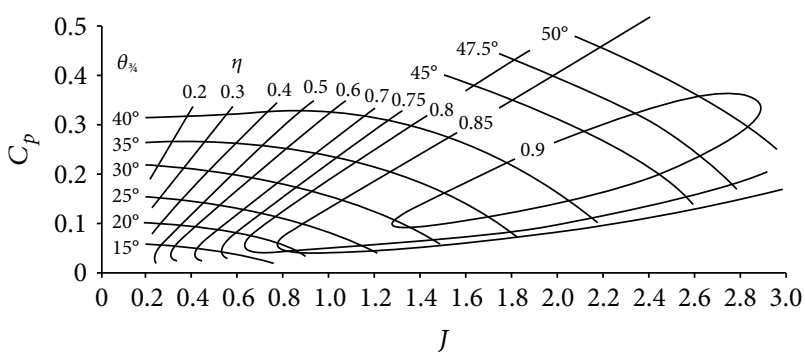

FIGURE 9: Efficiency characteristic curves of the propeller [21].

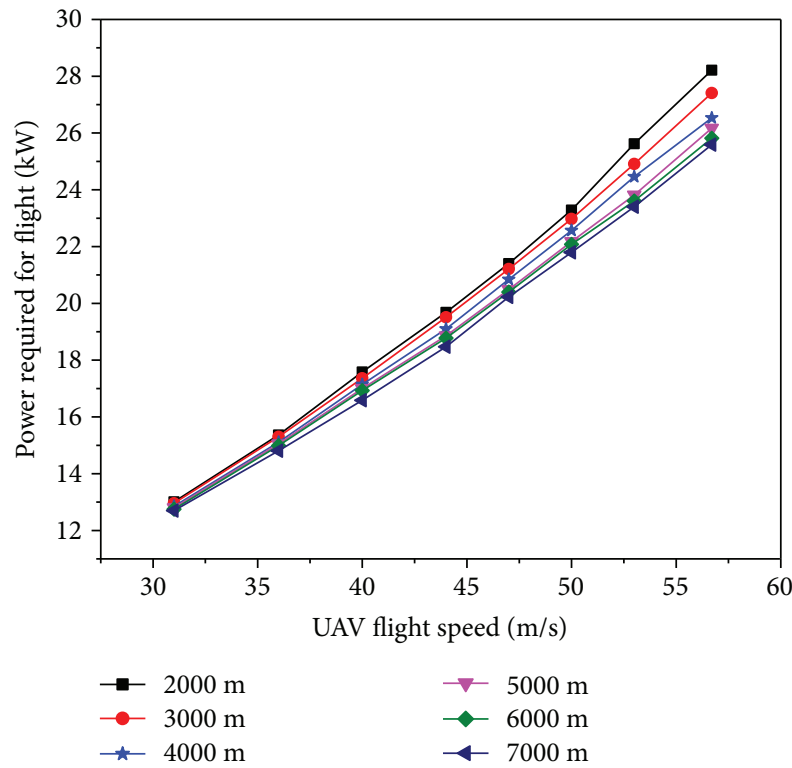

FIGURE 10: Power requirements for UAV flight at different altitudes.

When the UAV steadily rises linearly, the track azimuth $\varphi_{\text {fd }}$ and attack angle $\alpha$ are not very large, and the motion equation is simplified to

$$
\left\{\begin{array}{l}
T=D+G \sin \theta, \\
L=G \cos \theta,
\end{array}\right.
$$

where $T$ is the maximum thrust of the propeller, $L$ is the lift of UAV, and $D$ is the minimum resistance in a flying state. The climb rate is limited by the high-altitude characteristic and lift-drag ratio of UAV.

$\Delta T$ is the difference between the maximum thrust and the required thrust; $\Delta T_{\max }$ can be found in Figure 13. Thus, the change curves of the climbing rate at different altitudes are calculated (as shown in Figure 14).

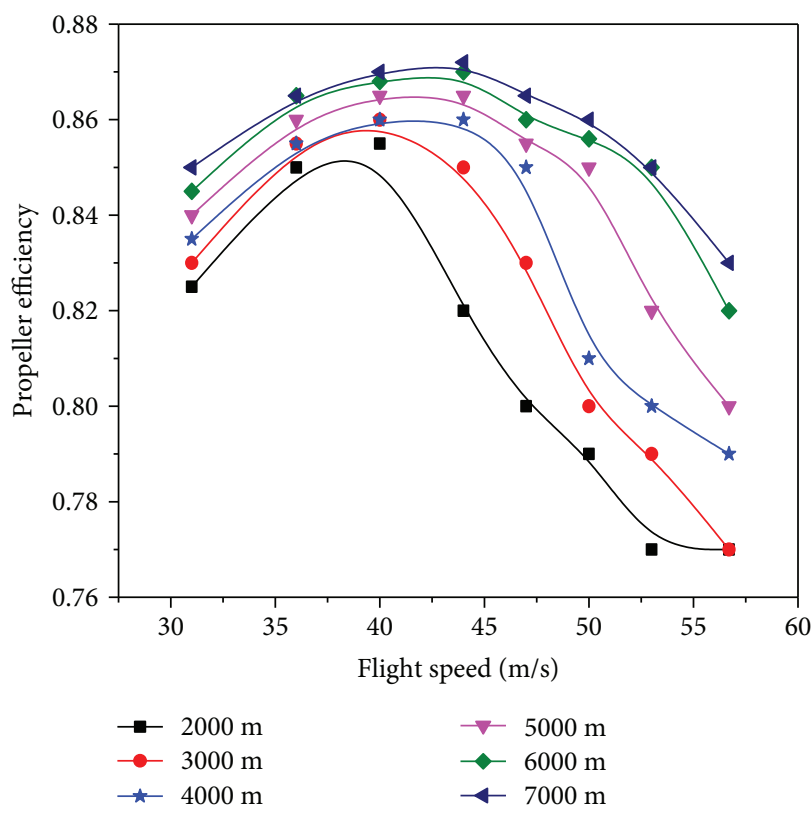

FIgURE 11: Curves of propeller efficiency at different altitudes.

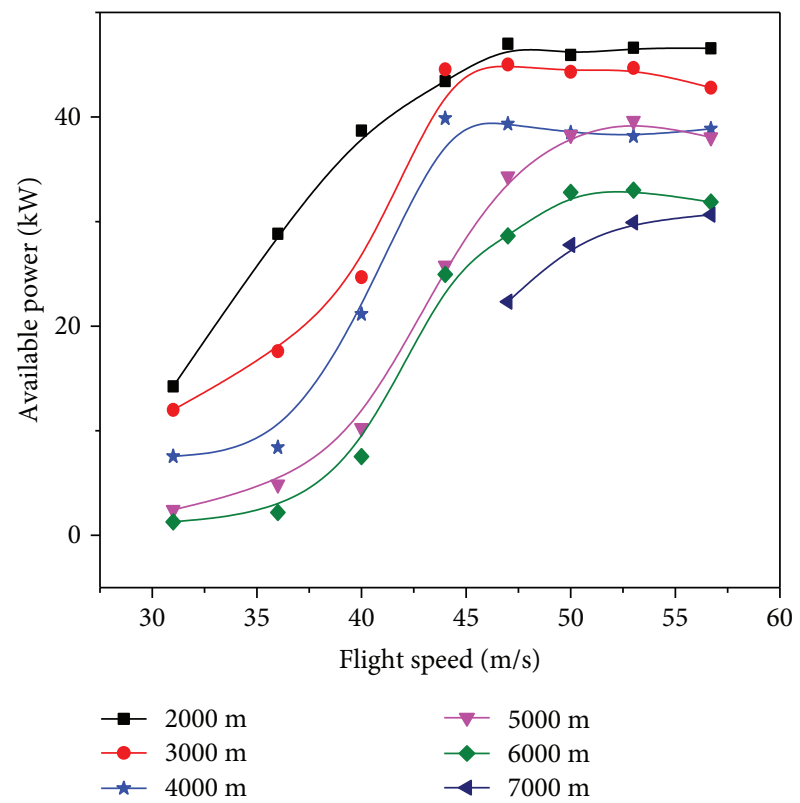

Figure 12: Curves of available power at different altitudes.

The climbing rate of UAV gradually decreases with increasing altitudes as shown in Figure 14, and the maximum value of $2.5 \mathrm{~m} / \mathrm{s}$ at $2000 \mathrm{~m}$ decreases to $0.5 \mathrm{~m} / \mathrm{s}$ at $7000 \mathrm{~m}$. It 


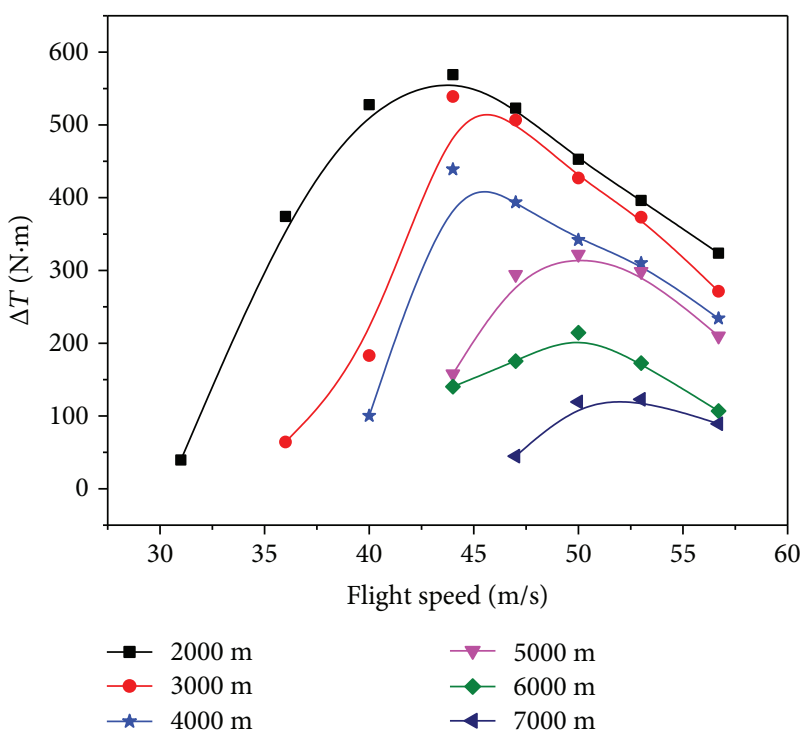

FIGURE 13: Thrust differences between available and required thrust at different altitudes.

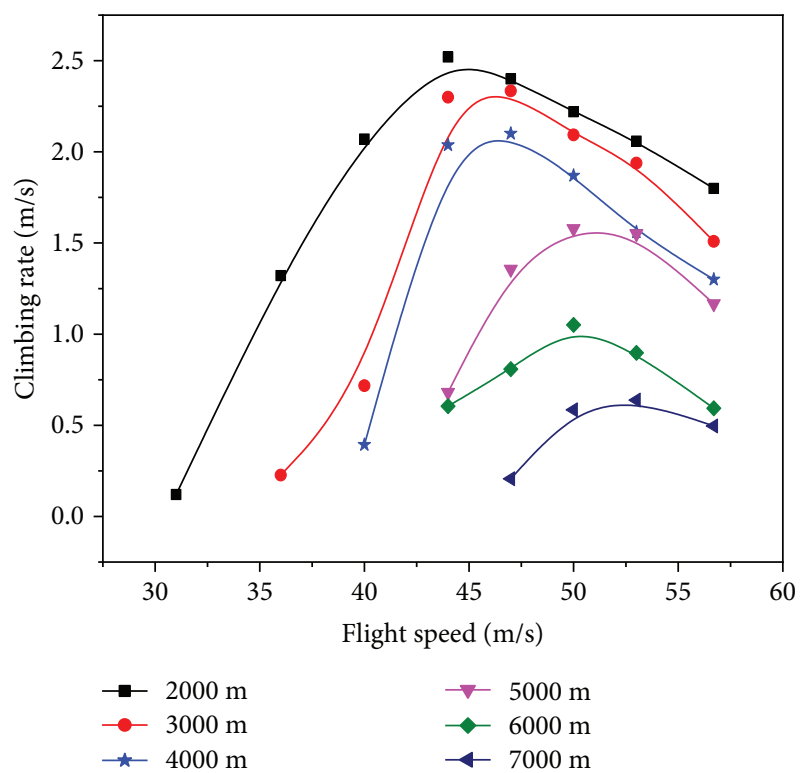

FIGURE 14: Climbing rates of UAV at different altitudes.

indicates that the climbing performance of UAV decreases significantly with increasing altitudes and the available flight speed range becomes narrow. The climbing rate increases first and then decreases with increasing flight speeds at the same altitude. The speed point corresponding to the maximum climbing rate moves to the right to guide route planning considering the maximum climbing mobility of UAV.

The hovering performance of UAV is evaluated by the horizontal turning radius $r$.

$$
r=\frac{m v^{2}}{L \sin \gamma}=\frac{v^{2}}{g} \cdot \frac{1}{\sqrt{(L / G)^{2}-1}},
$$

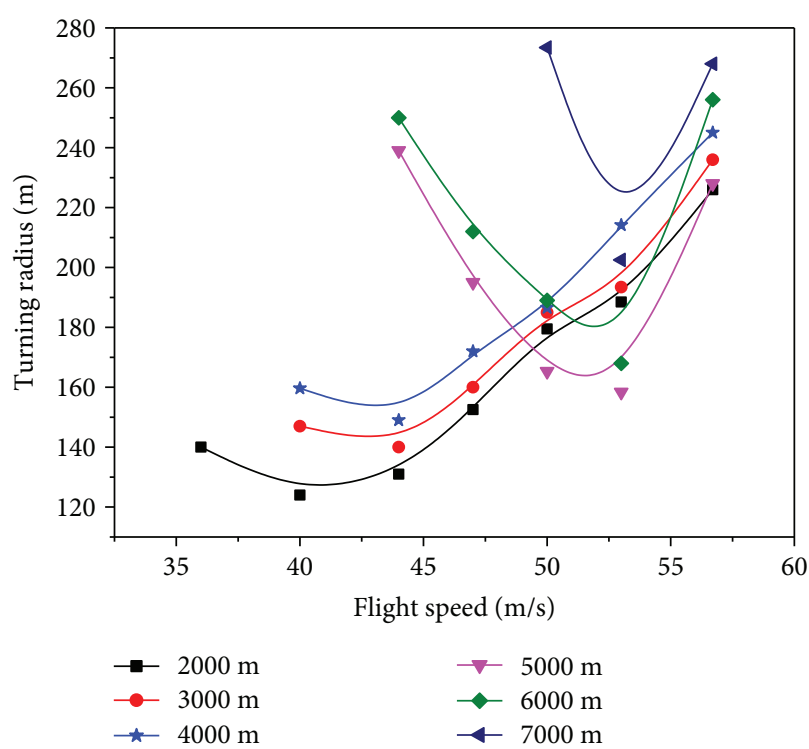

FIGURE 15: Turning radius of UAV at different altitudes.

where $\gamma$ is the turning angle, $v$ is the circumferential line velocity, and $L / G$ is the normal overload.

$L / G$ is replaced by $n_{Z}$ :

$$
r=\frac{v^{2}}{g} \cdot \frac{1}{\sqrt{n_{Z}^{2}-1}} .
$$

The required lift coefficient $C_{L}$ at this moment is as follows:

$$
C_{L}=\frac{2 n_{Z} G}{\rho v^{2} S}
$$

The resistance of UAV in horizontal hovering movement includes zero lift drag $D_{0}$ and induced drag $D_{\mathrm{i}}$ :

$$
D=\frac{1}{2} \rho v^{2} C_{D} S=D_{0}+D_{\mathrm{i}}=\frac{1}{2} \rho v^{2} S\left(C_{D_{0}}+A_{\mathrm{i}} C_{L}^{2}\right) .
$$

Among them, $C_{D_{0}}$ is the zero lift drag coefficient, $A_{\mathrm{i}} C_{L}^{2}$ is the induced drag coefficient, and $A_{\mathrm{i}}$ is the induced drag factor and is constant at subsonic velocity. The horizontal rotation radius of UAV at different altitudes $(2000 \mathrm{~m}$ $7000 \mathrm{~m}$ ) was calculated (as shown in Figure 15) in combination with formulas (12), (13), (14), and (15).

The turning radius increases with increasing altitudes when the flight speed is less than $52 \mathrm{~m} / \mathrm{s}$ as shown in Figure 15. When the speed is greater than $52 \mathrm{~m} / \mathrm{s}$, the turning radius increases first and then suddenly drops at the altitudes from $5000 \mathrm{~m}$ to $7000 \mathrm{~m}$. This is because the output power and induced drag decrease with increasing altitudes and the decrease in the induced drag is greater than that in the output power, reaching the maximum at the altitude of $5000 \mathrm{~m}$. The turning radius of UAV first decreases and then rises with increasing flight speed at the same altitude, and the flight velocity point corresponding to the minimum turning radius 


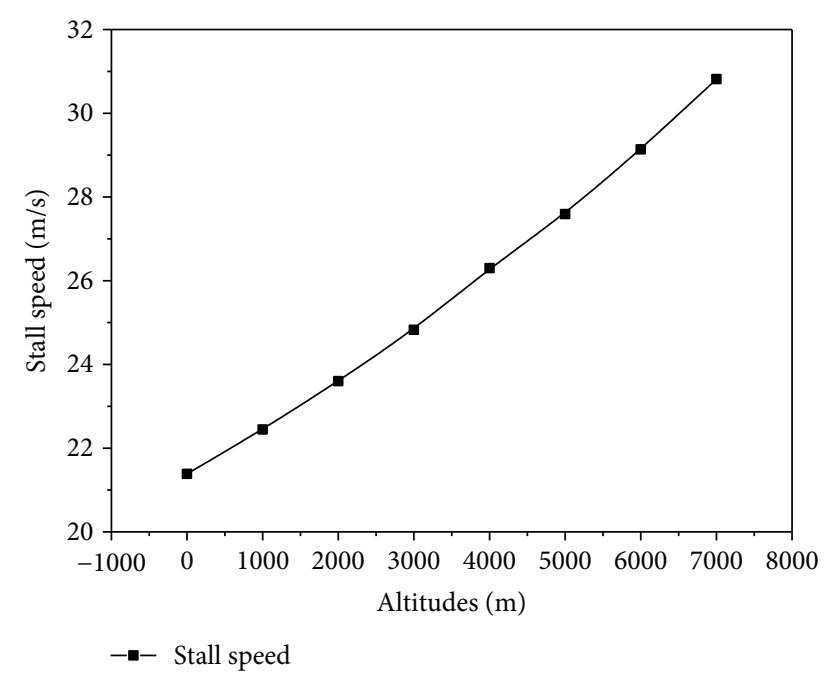

FIGURE 16: Stall speeds of UAV at different altitudes.

moves to the right, which is significant to guide the design of urgently changing direction and reconnaissance trajectory at a fixed spiral point.

3.3. High-Altitude Flight Envelope. The high-altitude flight envelope [24] is composed of the minimum flight speed, maximum flight speed, and rise limit, which indicates the flying range and flying limitation of UAV. The minimum flight speed is defined as the stall speed of UAV.

$$
V_{\min }=V_{s}=\sqrt{\left(\frac{2 m g / S}{\rho C_{L \max }}\right)},
$$

where $m$ is the average weight of $\operatorname{UAV}(\mathrm{kg}), C_{L \text { max }}$ is the maximum lift coefficient, and $S$ is the total area of UAV $\left(\mathrm{m}^{2}\right)$. The variation of the stall speed with altitudes was shown in Figure 16. The stall speed of UAV increases with increasing altitudes due to the decrease in the lift-drag ratio caused by an air density decrease at high altitudes.

The maximum horizontal flight speed $V_{\max }$ is mainly affected by the maximum available thrust of the engine, the weight of the UAV, and the structural strength.

$$
V_{\max }=\sqrt{\frac{2 T_{\max }}{C_{D} \rho S}} .
$$

The available lift is the maximum height of UAV maintaining a certain climbing ability, which is defined as the flight height of UAV at a maximum climbing rate of $0.5 \mathrm{~m} / \mathrm{s}$.

The maximum flight velocity of UAV at different altitudes was shown in Figure 17. The maximum flight velocity decreased with increasing altitudes and decreased in large amplitude at the altitudes between $3000 \mathrm{~m}$ and $5000 \mathrm{~m}$. It is because the resistance coefficient increased with decreasing air density at high altitudes, especially at altitudes of $3000 \mathrm{~m}-5000 \mathrm{~m}$.

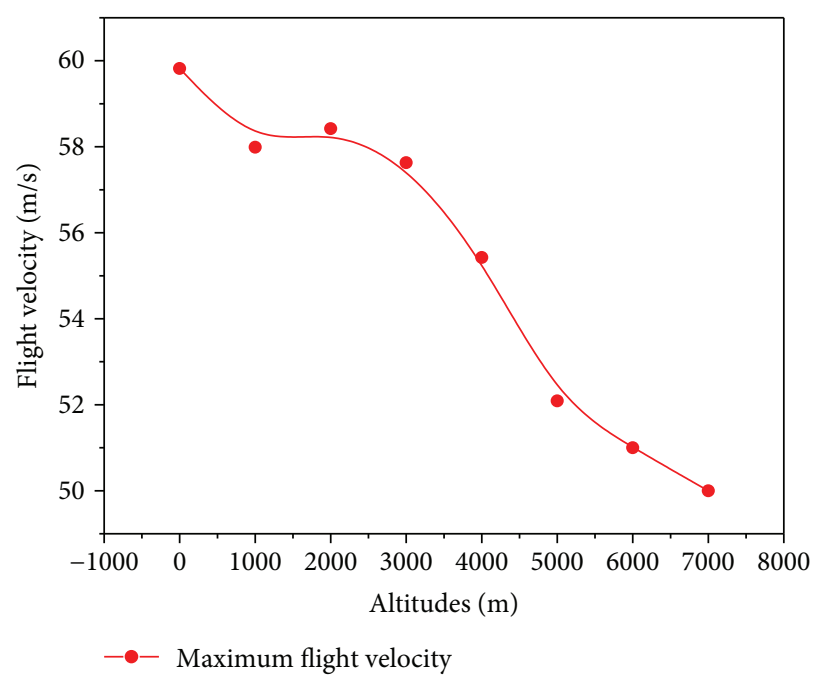

FIGURE 17: Maximum flight velocity of UAV at different altitudes.

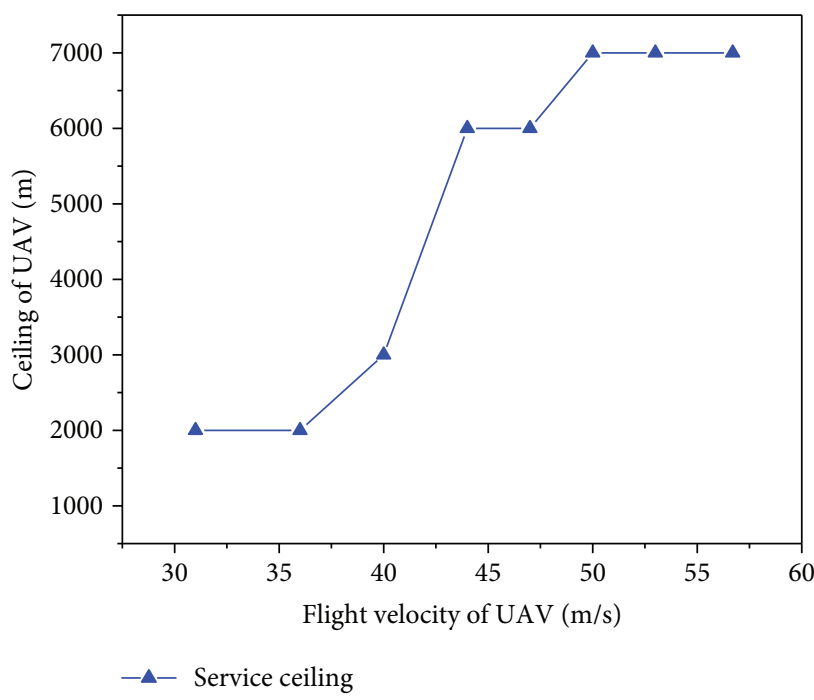

FIGURE 18: Service ceiling of UAV.

Ceiling of UAV includes absolute ceiling and service ceiling. The service ceiling was viewed as the maximum height when UAV maintain a certain climbing ability. As shown in Figure 18, the service ceiling was low under low-speed operating conditions. The service ceiling increased with increasing flight velocity and reached to $7000 \mathrm{~m}$ when the velocity is above $50 \mathrm{~m} / \mathrm{s}$.

The flight envelope was shown in Figure 19. The maximum flying lift is $7000 \mathrm{~m}$ at flight speeds between $47 \mathrm{~m} / \mathrm{s}$ and $52 \mathrm{~m} / \mathrm{s}$. The maximum flight speed is about $57 \mathrm{~m} / \mathrm{s}$, and the minimum flight speed is about $30 \mathrm{~m} / \mathrm{s}$ at the altitude of $2000 \mathrm{~m}$.

3.4. High-Altitude Endurance. Endurance performance of UAV contains maximum flying distance and maximum endurance time.

The maximum thrust of the piston gasoline engine was identified as the actual thrust when UAV is in cruise flight. 


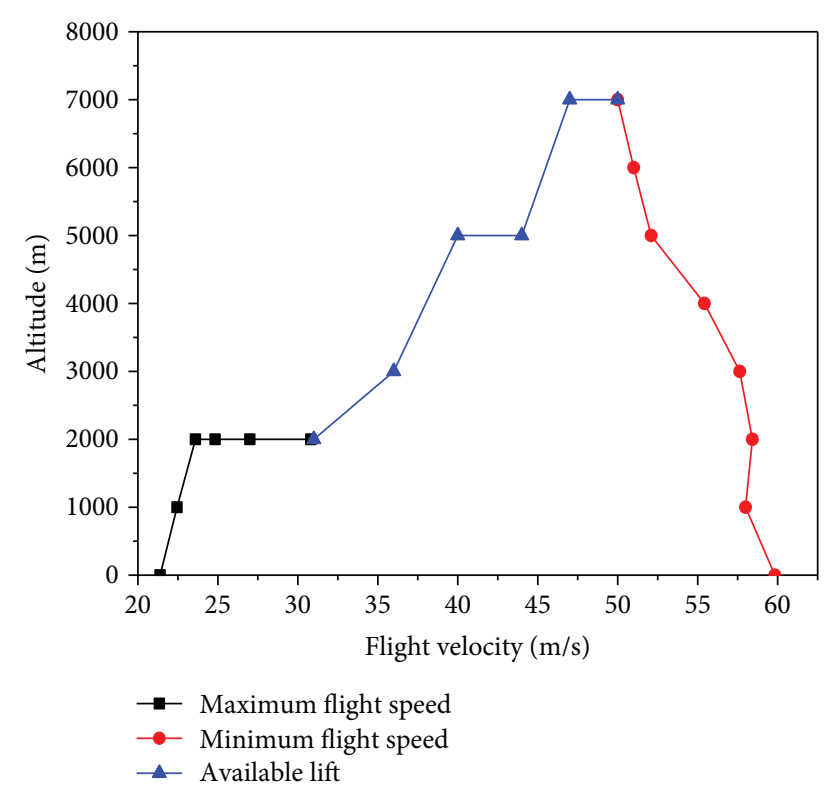

Figure 19: Flight envelopes of UAV.

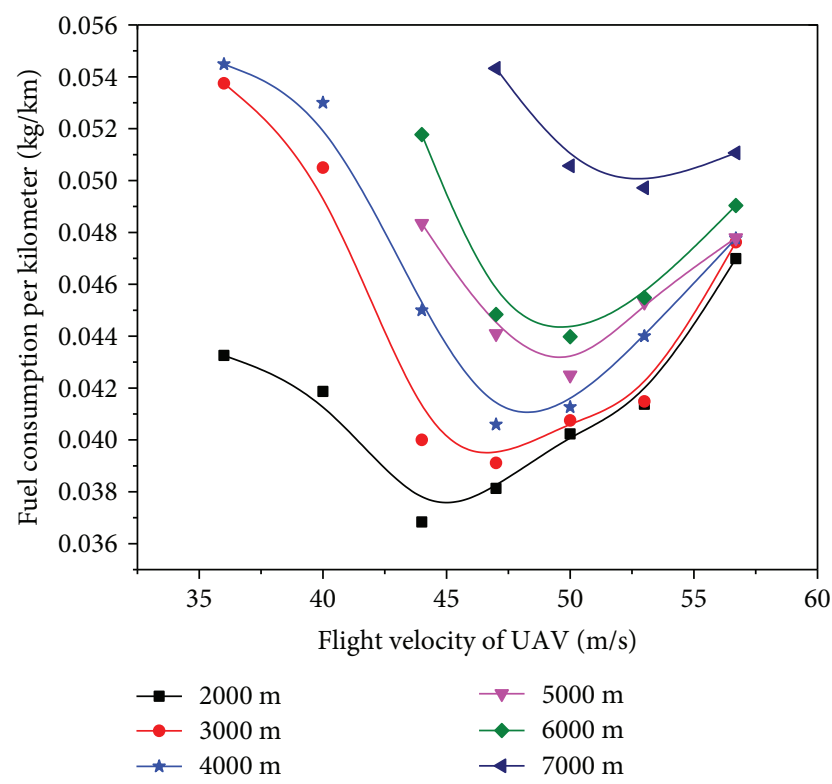

Figure 20: Fuel consumption per kilometer of UAV at different altitudes.

Fuel consumption per kilometer of UAV was calculated as follows:

$$
q_{L}=\frac{C_{\mathrm{e}} P_{x}}{\eta v},
$$

where $C_{\mathrm{e}}$ represents the specific fuel consumption of the engine $(\mathrm{g} /(\mathrm{kW} \cdot \mathrm{h})), P_{x}$ represents the required thrust when $\mathrm{UAV}$ is flying $(\mathrm{N} \cdot \mathrm{m}), \eta$ represents the propeller efficiency, and $v$ represents the cruising speed $(\mathrm{m} / \mathrm{s})$.

The weight of UAV takes the average of full weight at the takeoff stage and the weight with $5 \%$ oil volume at the landing

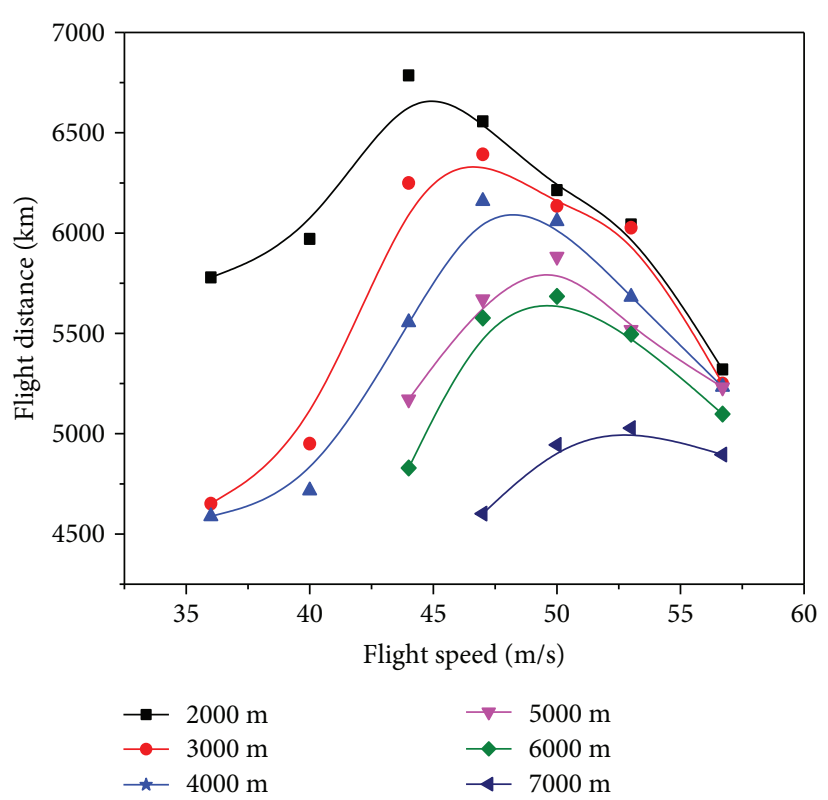

FIgURE 21: Maximum flight distance at different altitudes.

stage. We chose $m=870 \mathrm{~kg}$. The specific fuel consumption of UAV was calculated by formula (18), as shown in Figure 20.

The flying distance of UAV at a certain cruise altitude can be expressed as

$$
L_{h v}=\frac{\Delta m_{T}}{q_{L}},
$$

where $\Delta m_{T}$ is the weight of UAV at $95 \%$ of oil under full load and $q_{L}$ is the fuel consumption rate per kilometer.

The maximum flying distance of UAV was calculated by formula (19) (as shown in Figure 21). The maximum flight distance decreases with increasing altitudes: the flight distance value of $6800 \mathrm{~km}$ at $0 \mathrm{~m}$ decreases to $4800 \mathrm{~km}$ at $7000 \mathrm{~m}$. The farthest distance rises first and then decreases with increasing flight speed at the same altitude. This is mainly because the fuel consumption rate and the drag coefficient of UAV first decrease and then rise with increasing flight speed resulting in the tendency of fuel consumption per kilometer.

The cruise time of UAV can be calculated using the cruising distance at a certain altitude and the flight speed (as shown in Figure 22). Flight time significantly decreases with increasing altitudes. The maximum flight time of $45 \mathrm{~h}$ at $0 \mathrm{~m}$ decreases to $27 \mathrm{~h}$ at $7000 \mathrm{~m}$. The flight time decreases with increasing flight speed at a fixed altitude and decreases sharply when the flight speed exceeds $45 \mathrm{~m} / \mathrm{s}$.

\section{Conclusion}

The paper analyzed the influence of an opposed-piston gasoline engine on the flight performance of a UAV by the engine simulation test and theoretical derivation and obtained the variation rules of the propeller thrust characteristics, maneuverability, flight envelope, flight distance, and time of the UAV. 


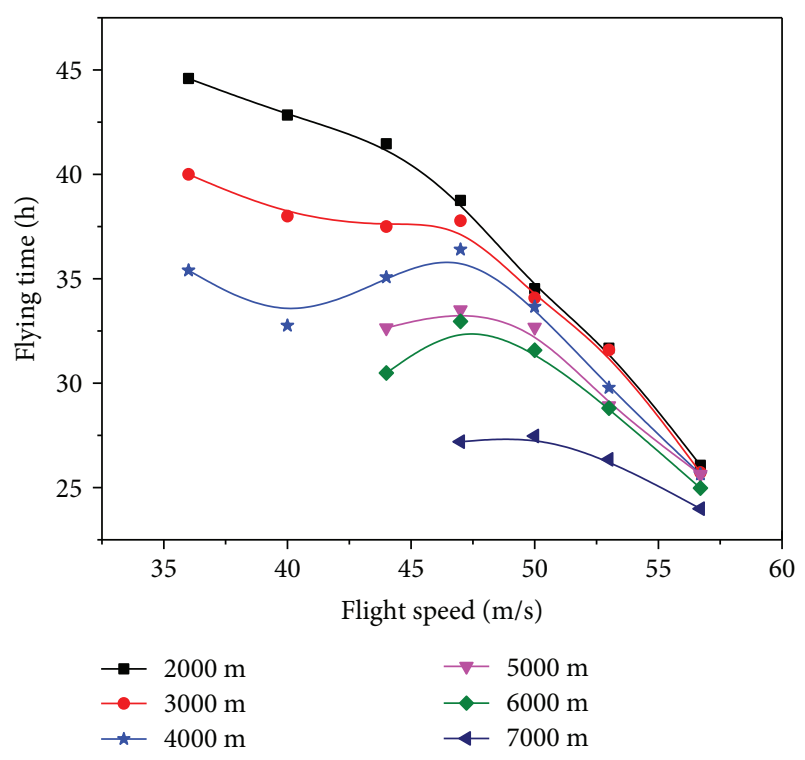

Figure 22: Maximum flight time at different altitudes.

(1) The trend of the propeller thrust characteristic is different from that of the output power with increasing altitudes. The output power of the engine increases with increasing flight speed, but the available power has a "turning point" with increasing flight speed, and the available power remains unchanged when the flight speed exceeds the "turning point"

(2) The climbing rate of UAV gradually decreases with increasing altitudes. The maximum climbing rate of $2.5 \mathrm{~m} / \mathrm{s}$ at $2000 \mathrm{~m}$ decreased to $0.5 \mathrm{~m} / \mathrm{s}$ at $7000 \mathrm{~m}$, and the speed area with a climbing rate was greater than that at $0 \mathrm{~m}$ and the available flight area reduces

(3) The available lift limit of UAV is lower under lowspeed operating conditions. The lift limit increases with increasing flight speed, and the limit reaches $7000 \mathrm{~m}$ when the flight speed exceeds $50 \mathrm{~m} / \mathrm{s}$. The maximum flying height of the UAV is about $7000 \mathrm{~m}$ with a flight speed range of $47 \mathrm{~m} / \mathrm{s}-52 \mathrm{~m} / \mathrm{s}$, and the maximum and minimum flight speeds are $57 \mathrm{~m} / \mathrm{s}$ and $30 \mathrm{~m} / \mathrm{s}$ with the flight envelope

(4) The maximum distance and flight time of UAV decrease with increasing altitudes, and the distance and time decrease by $5.8 \%$ and $8 \%$, respectively, for every $1 \mathrm{~km}$ rise in altitude. The flight distance first increases and then decreases with increasing flight speed at a fixed altitude. The flight time decreases, especially when the flight speed exceeds $45 \mathrm{~m} / \mathrm{s}$

\footnotetext{
Abbreviations

CP: Control system of intake and exhaust pressure

DS: Data acquisition system

ECS: Engine combustion analysis system

EB: Exhaust pressure stabilizing box

ES: Engine control system
}

EV: Electric butterfly valve

FM: Fuel consumption meter

HE: Heat exchanger

IB: Intake pressure stabilizing box

VP: Vacuum pump.

\section{Data Availability}

The data used to support the findings of this study are available from the corresponding author upon request.

\section{Conflicts of Interest}

The authors declare that there is no conflict of interests regarding the publication of this paper.

\section{Acknowledgments}

The authors would like to thank Tianjin University for providing technical support. The authors state that the research and publication of the article were funded by the project named "Experimental research on aero-engine at simulated high altitudes," and the project's number is 2016B46 with a total funding of three hundred thousand yuan.

\section{Supplementary Materials}

Supplementary materials are experimental data of the UAV engine in the form of tables to support test curves and tables of the manuscript. (Supplementary Materials)

\section{References}

[1] Office of the Secretary of Defense, FY2009-2034 Unmanned Systems Integrated Roadmap, DOD, Washington, DC, USA, 2009.

[2] C. Jenks, "Law from above: unmanned aerial systems, use of force, and the law of armed conflict," North Dakota Law Review, vol. 85, p. 649, 2010.

[3] M. Weinberg and J. Wyzykowski, "Development and testing of a commercial turbofan engine for high altitude UAV applications," in SAE Technical Paper 2001-01-2972, SAE International, Warrendale, PA, USA, 2001.

[4] B. Yu, Research and Application of Mission Planning for Hollow Long Endurance UAV, Chengdu University of Electronic Science and Technology, Chengdu, China, 2013.

[5] L. Techy, C. A. Woolsey, and D. G. Schmale, "Path planning for efficient UAV coordination in aerobiological sampling missions," in 2008 47th IEEE Conference on Decision and Control, pp. 2814-2819, Cancun, Mexico, 2008.

[6] Z. B. Liu, Aerodynamics of $U A V$, Aviation Industry Press, Beijing, China, 2006.

[7] L. Ruilin, Study on Adaptability of Diesel Engine to Plateau Environment, Beijing Institute of Technology Press, Beijing, China, 2013.

[8] B. Liu and K. Deng, "Calculation study on power recovery of two stroke gasoline engine at elevated altitude," Journal of Aeronautics and Power, vol. 24, no. 7, pp. 1570-1576, 2009.

[9] P. Wang, Design and Experimental Study of a UAV Propeller, Harbin Institute of Technology, 2017. 
[10] P. Shan, Y. Zhou, and D. Zhu, "Mathematical model of two-stage turbocharging gasoline engine propeller propulsion system and analysis of its flying characteristic," Journal of Engineering for Gas Turbines and Power, vol. 137, no. 5, article 051201, 2015.

[11] T. Zijie, D. S. Ting, D. Farong, Z. Qi, and Z. Wanbing, "Study on the matching between aero two stroke piston engine and fixed pitch propeller," Journal of Aeronautics and Power, vol. 25, no. 2, pp. 379-383, 2010.

[12] L. Manqun, W. Guowen, Z. Shizhi, Z. Maolei, and Y. Xicheng, "Experimental study on propeller-engine matching of UAV propulsion system," Aerospace Manufacturing Technology, vol. 6, no. 3, pp. 1-9, 2016.

[13] Y. Zhang, "A study on the available power of propeller-driven small UAV," Science Technology and Engineering, vol. 11, no. 8, pp. 1876-1880, 2011.

[14] X. Ma and B. Song, "Practical measures for raising propeller efficiency of low speed mini UAV," Journal of Northwestern Polytechnical University, vol. 2, pp. 209-212, 2004.

[15] H. Wang, J. Li, W. Fu, and Z. Zhou, "Aerodynamic design of propeller for unmanned aerial vehicles," Chinese Journal of Applied Mechanics, vol. 4, pp. 380-385, 2012.

[16] Y.-L. He, L.-B. Lu, and X. Wang, "A type of UAV engine dynamics modeling and simulation," Fire Control and Command Control, vol. S1, pp. 44-45, 2008.

[17] J. M. Hallissy and J. J. Chattot, "Validation of helicoidal vortex model with the NREL unsteady aerodynamic experiment," in 43rd AIAA Aerospace Sciences Meeting and Exhibit, pp. 1-11, Reno, NV, USA, 2005, AIAA.

[18] A. Smedresman, D. Yeo, and W. Shyy, "Design, fabrication, analysis, and dynamic testing of a micro air vehicle propeller," in 29th AIAA Applied Aerodynamics Conference, pp. 1-16, Honolulu, HI, USA, 2011, AIAA.

[19] W.-J. Zhang, Study on High-altitude Performance of an Opposed-Piston Gasoline Engine and Its Influence on Flight Performance of UAV, Army Military Transportation University, Tianjin, China, 2015.

[20] R.-L. Liu, "High altitude simulation test bench for engine thermal balance," ZL20101051 3573.6, China, 2012.

[21] G.-M. Zhou, C.-H. Yang, L.-Y. Chen et al., "High-altitude thermal balance characteristics of the boxer piston engine," Equipment Environmental Engineering, vol. 14, no. 10, pp. 58-62, 2017.

[22] P. Liu, Theory and Application of Air Propeller, Aerospace Industry Press, Beijing, China, 2007. 


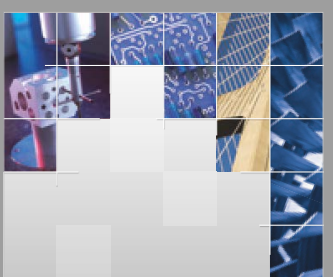

\section{Enfincering}
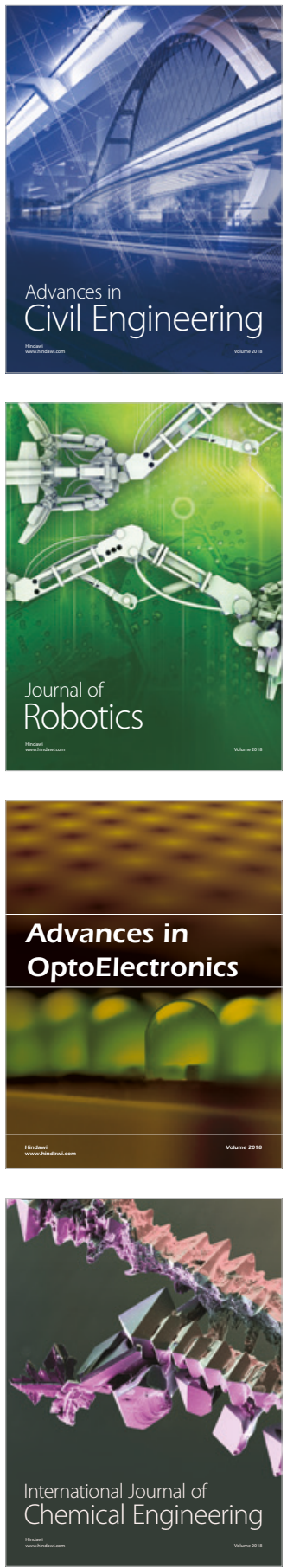

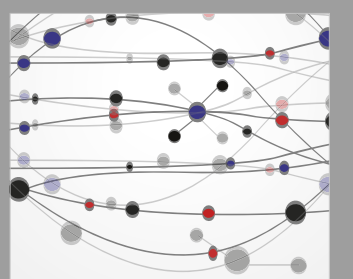

\section{Rotating \\ Machinery}

The Scientific World Journal

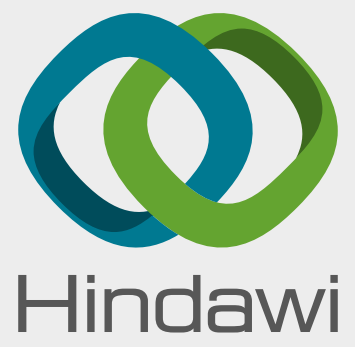

Submit your manuscripts at

www.hindawi.com
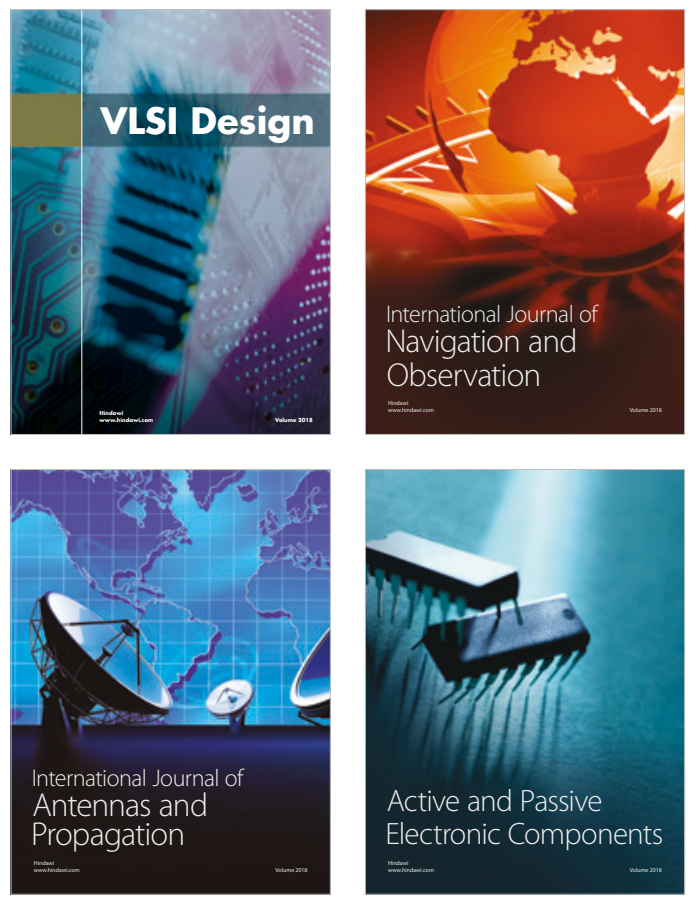
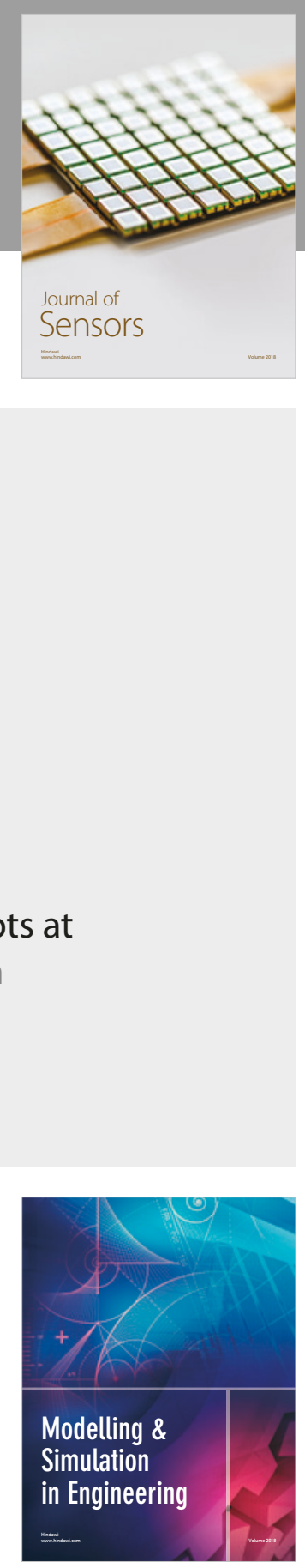

\section{Advances \\ Multimedia}
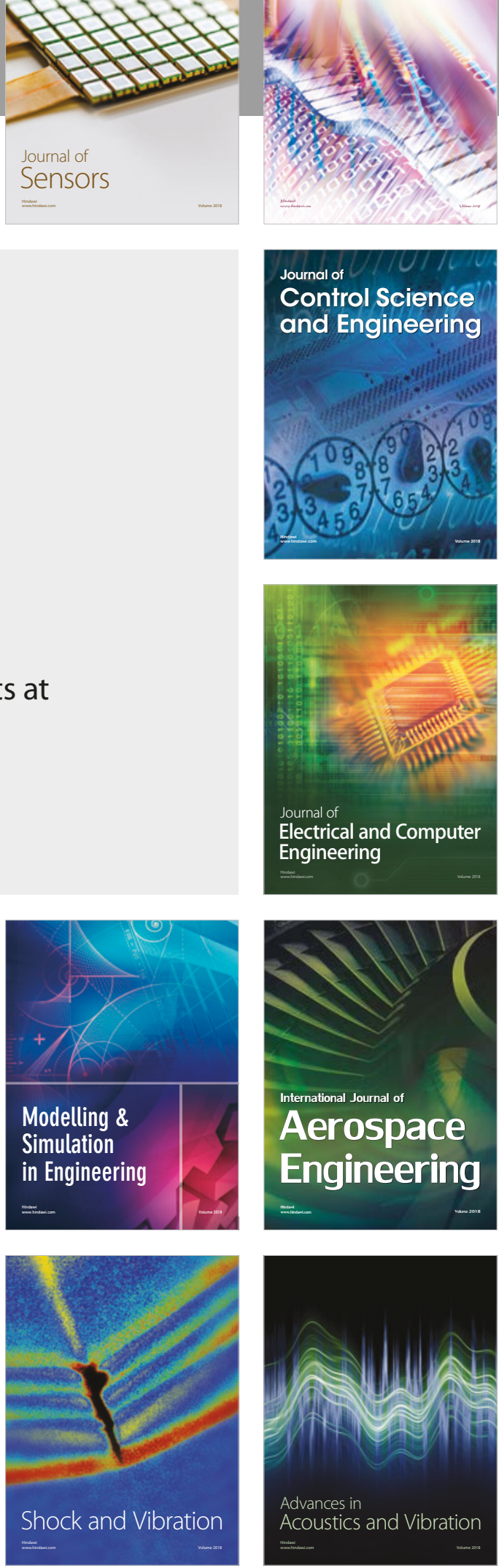